\title{
FIELD TRIAL TO ASSESS POSSUM PREFERENCE FOR A NEW PEST CONTROL PASTE
}

\author{
B. JORDAN ${ }^{1}$, H. MOLLER ${ }^{2}$ and G. HICKLING ${ }^{3}$ \\ ${ }^{1}$ Taranaki Regional Council, Private Bag 713, Stratford \\ ${ }^{2}$ Department of Zoology, PO Box 56, University of Otago, Dunedin \\ ${ }^{3}$ Department of Entomology and Animal Ecology, PO Box 84, Lincoln University
}

\begin{abstract}
A field trial (using Rhodamine B and green glitter markers) was carried out to test the preference of a fruit paste bait currently used for possum(Trichosurus vulpecula)control against a new paste formulation constituted to improve cohesiveness and preservation of the paste. Bait takes on spit lines, faecal pellets collected from the field, and post mortem analysis of possum samples all showed the new paste to be preferred to the old formulation. We therefore predict that acceptance of the new paste formulation by possums is greater than the paste currently in use.
\end{abstract}

Keywords: paste, possum control, preference, acceptance

\section{INTRODUCTION}

Cheap and effective methods of controlling brushtail possums (Trichosurus vulpecula) are needed for protection of domestic stock (especially cattle and deer) from bovine tuberculosis, for the protection of economic values (ie crops, pine trees, pasture etc.) and for protecting conservation values of New Zealand's indigenous forests (PCE 1994).

Fruit paste bait is an important tool for possum control operations in situations where aerial application of solid baits is impractical or hazardous. The main ingredient for this type of paste is usually apple pulp with a preservative, binding agent and toxin (usually sodium monofluoroacetate, 1080) added. The bait is hand-applied to raised bait stations or on the ground along spit lines (turf of dirt turned upside down every $3 \mathrm{~m}$ ), most often along margins of scrub or forest patches, or as a follow up "maintenance control" operation around large patches previously poisoned by aerial application.

In recent years there has been increasing concern about the cost of paste and its attractiveness to honey bees (Apis mellifera), with consequent risk of 1080 contamination in honey. The Taranaki Regional Council (TRC) therefore developed a more costeffective paste (Leckie 1993) that was unattractive to bees (Jordan 1994; Morgan and Goodwin 1995). That paste (called the "old paste" in this report) has since been accepted by Taranaki's Medical Officer of Health as safe for possum control around active beehives.

A number of problems were found with the old paste, including its lack of cohesiveness. Therefore a modified formulation of the paste was developed with a binding agent added and alterations to preservative levels to deal with these issues (hereafter referred to as the "new paste"). A field trial was then conducted to ensure that its preference by possums was at least as high as for the old paste.

\section{MATERIALS AND METHODS}

Sixteen study sites spread over 56 hectares in Tariki (North Taranaki) were chosen for the preference experiment. Sites generally consisted of dairy pasture/ bush edges (mixture of native trees combined with scrub including blackberry and gorse) often with small creeks flowing through them. Each site had moderate to high possum densities (610 possums per hectare), with little or no previous possum control. The sites were chosen so that at least 6 possum carcasses could be collected from each (approximately 250-400 
$\mathrm{m}$ length blocks depending on the possum density).

A minimum of $600 \mathrm{~m}$ between most study sites minimised the chance of possums taking baits from more than one area (Hickling et al. 1990). Adjacent sites within $600 \mathrm{~m}$ of each other had a natural barrier to possums between them, for example a river.

Rhodamine B dye (Animal Control Products Ltd) and green glitter (Draw Art Supplies Ltd) were used as markers to identify paste types eaten during the experiment following their successful use in earlier trials (Evans and Griffith 1973; Morgan 1981).

At each site, the pastes were randomly allocated one of the two markers. Each of the two pastes contained each dye in 8 of the 16 study sites, to prevent any possible bias had one of the markers affected preference.

The pastes were also lured with cinnamon oil as this is attractive to possums (Morgan et al. 1995) and is often used for possum control. The pastes had the marker and cinnamon oil mixed into them the day before they were put out in the field. Rhodamine $\mathrm{B}$ dye was mixed into the paste at $2 \% \mathrm{w} / \mathrm{w}$, a level that was considerably higher than the recommended amount of dye for possum trials using pellets (Morgan 1981). This protocol was chosen because an earlier experiment had shown that at $1.5 \% \mathrm{w} / \mathrm{w}$ the dye was very hard to detect three days after the paste was eaten, probably because of the high water content of pastes compared to pellets (Ellis 1996). The green glitter was mixed at a rate of $5 \% \mathrm{w} / \mathrm{w}$.

Equal amounts of each paste ( $8 \mathrm{~g}$ baits) were placed in the study sites using the Taranaki Regional Councils standard procedure for a control operation on spit lines and also in small plastic bait stations at $25 \mathrm{~m}$ intervals in June 1996. Each of the two formulations of paste were placed on alternate spits and in alternate bait stations in each study site.

Baits were checked daily for 3 days and any completely or partially eaten baits were recorded and replaced.

From day 3 to day 6 after laying the paste baits possums were collected by trapping (using Victor 1+inch Soft-Catch traps), cyanide poison placements and shooting (using .22 calibre rifles fitted with silencers). The cyanide baits and half of the traps (chosen randomly) were lured with orange and aniseed. Different lures were used in these baits than in the laying of paste to prevent a possible bias in the sampling. Orange and aniseed were chosen as both have been found highly acceptable to possums (Morganet al. 1995). The remainder of the traps were set to possum sign (i.e., without lure) and shooting was used to minimise any possible bias arising from using only lures to sample the possum population.

Each possum was inspected for Rhodamine B or green glitter around the mouth, fore-paws, anus, and within stomach contents. If no marker or only one marker was found in the stomach contents, then faecal pellets were removed from the rectum and searched for markers. An ultra-violet light and alcohol were used to help detect Rhodamine B dye, as this illuminates the dye.

On day 6 faecal pellets were gathered randomly from the ground at each study site and inspected for markers. Most pellets were gathered within a few metres from baits with none were gathered more than $50 \mathrm{~m}$ from the nearest bait.

Paired t-tests were used to determine whether the number of new and old baits taken was the same within all 16 sites.

\section{RESULTS}

A mean of 6.62 more new baits (per 100 baits per night) were taken per site than old baits $(t=3.28, d f=15, P<0.005$; Table 1$)$. Similarly a mean of 0.69 more new baits were taken than old baits within bait stations; but this difference was not significant $(\mathrm{t}=0.87$, $\mathrm{df}=15, \mathrm{P}=0.397$; Table 1).

Faecal pellets (1044) were collected from the 16 sites. A paired t-test was carried out to test the null hypothesis that an equal number of pellets had markers from new or old pastes. A mean of 1.69 more pellets containing the new paste were found than the number of pellets containing old paste per study site $(\mathrm{t}=3.391, \mathrm{df}=15, \mathrm{P}=0.004)$.

TABLE 1: The percentage of new and old paste baits taken, partly taken and not taken over the three nights from spit lines and bait stations at 16 
sites. The $95 \%$ binomial confidence limits given in parentheses were calculated from Mainland et al. (1956).

\begin{tabular}{lcccc}
\hline & & \% Taken & \% Partly taken & $\begin{array}{c}\text { \% Not } \\
\text { taken }\end{array}$ \\
\hline Spit lines & old paste & 65.9 & 6.6 & 27.5 \\
& & $(64-69)$ & $(5-8)$ & $(25-29)$ \\
& new paste & 72.4 & 5.0 & 22.6 \\
& & $(70-74)$ & $(4-6)$ & $(20-24)$ \\
& P (t - test) & 0.005 & 0.636 & 0.001 \\
Bait stations & old paste & 63.0 & 6.9 & 30.1 \\
& & $(56-70)$ & $(3.5-11.5)$ & $(23-27)$ \\
& new paste & 69.8 & 6.2 & 23.9 \\
& & $(63-87)$ & $(2.4-9.8)$ & $(18-31)$ \\
& P (t -test) & 0.397 & 0.383 & 0.410 \\
\hline
\end{tabular}

The results indicate that possums show a preference for new paste over the old paste. This trend was reflected in a greater overall proportion of carcasses with sign of markers from new and old pastes (Fig. 1). However, most of this difference was detected in comparisons of stomach contents alone, and old paste was sometimes more prevalent at other places on the carcasses. However stomach contents were by far the most common place of detection (Fig. 1). If the number of detections in faecal pellets from the rectum (only sampled if no sign in the stomach) is added to the stomach contents prevalence, then every possum with marker somewhere is included i.e no possums had marker on their mouth, paws or anus without having sign in their gut contents.

Whenever there was a difference between the percent of possums showing sign of having consumed the new or old paste at a given place on the body, there were always more

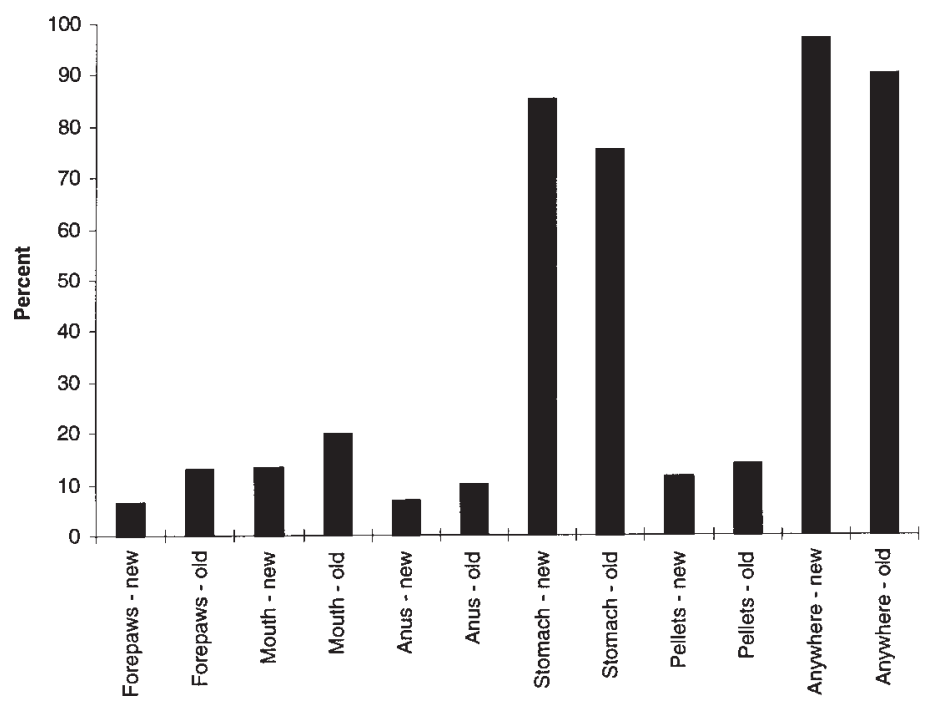

FIGURE 1: Percentage of possums with marker dye at various locations, for both paste formulations $(n=144$ possums sampled $)$. 
possums with Rhodamine B than green glitter (with the single exception of pellets taken from the rectum for old paste). Differences between Rhodamine B and green glitter were greater for old paste compared to new paste. Throughout the sampling, Rhodamine B dye was easier to detect than green glitter as Rhodamine B was readily illuminated by the ultra violet light. This was reflected in a higher proportion of sites with Rhodamine B than glitter when considering each paste type separately.

\section{DISCUSSION}

Rhodamine B was easier to detect than green glitter and in future studies green glitter is not recommended for use in baits that have a high water content unless possums can be sampled within 72 hours of consuming the bait. When preference between two baits laid out in the same area is being compared, it is essential that equal numbers of study areas with each marker in the other bait type are used.

Bait preference cannot be estimated reliably from marking of the paws, mouth or anus of live animals. Post mortem and inspection of stomach contents was the most reliable technique.

The results from the spit lines, faecal pellets and possum carcasses show a consistent and statistically significant pattern of increased preference for the new paste relative to the old bait. The bait stations data showed the same trend although this was not statistically significant, perhaps because of the relatively low number of bait stations in each area.

This trial measured "preference" (palatability when offered the choice between two materials - not a true measure of bait take) rather than "acceptance" (proportion of the population that eats the bait) of the new and old pastes because both pastes were laid out together in the same site. An initial power analysis was performed using a design in which some areas were treated only with new paste and other areas only with old paste. The analysis predicted that a huge and impractical number of possums and areas would need to be sampled to detect a modest increase in acceptance of the new paste. Accordingly the next best design, using markers and both pastes in the same area, was chosen. Increased statistical power resulted from the paired comparisons, but the trial could only then measure preference between the two paste types. However, it seems reasonable to assume that relative preference will predict relative acceptance.

This study thus suggests that the new paste is at least as acceptable to possums as the old one, and is potentially more acceptable. This should now be confirmed by careful monitoring of poisoning campaigns using the new paste, and a statistical comparison of effectiveness of these new operations with those conducted using the old paste in the recent past.

This new TRC paste should replace the paste currently in use. The new paste is preferred by possums and is not taken by honeybees (Jordan 1996). The addition of a suitable binding agent means that the bait maintains its consistency for longer in the field (B. Jordan; pers. obs.) and it has a satisfactory shelf life. The new paste is also more convenient to extrude through application equipment and there is less leakage, so it should be safer to use and pose less risk to non-target species.

Research in which species other than possums take the new bait would be valuable. For example, ferrets (Mustela furo) and probably hedgehogs (Erinaceus earopaeus) are killed by old Animal Control Products 1080 jam paste baits (Moller et al. 1996a). Unintentional control of ferrets may assist bovine tuberculosis control but could result in increased rabbit numbers (Molleret al. 1996b). Trials need to be carried out to identify whether this new formulation is acceptable to rabbits. If so, then this paste may prove to be a more cost effective method for rabbit control.

With the ever increasing risk of non tariff trade barriers threatening the economic viability of our agricultural based industries, the need for effective, safe methods of possum control becomes greater. This trial has identified a more effective and efficient bait.

\section{ACKNOWLEDGEMENTS}

Thanks to the Taranaki Regional Council for the financial assistance and support they provided for this study, with special thanks to TRC staff George Gallop, Steve Ellis, 
Campbell Leckie and John Humphrey. We thank Caryn Thompson for her statistical advice and all the farmers involved in allowing access to the study sites.

\section{REFERENCES}

Ellis, S., 1996. Rhodamine dye paste trial. Taranaki Regional Council Report 2pp.

Evans, J., and Griffith, R.E.,1973. A fluorescent tracer and marker for animal studies. Wildlife Management 37: 73-81.

Hickling, G.J., Thomas, M.D., Grueber, L.S., and Walker, R., 1990. Possum movements and behaviour in response to self-feeding bait stations. Forest Research Institute Contract Report FWE90/9. 17pp.

Jordan, B., 1994. Bee experiment. Taranaki Regional Council Report. 2pp.

Jordan, B., 1996. Trial to assess whether honeybees (Apis mellifera) are attracted to the TRC's fruit paste bait formulation for possum control. Taranaki Regional Council Report. 8pp.

Leckie, C., 1993. Alternative feed paste. Taranaki Regional Council Report. 3pp.

Mainland, D., Herrera L., and Sutcliffe HI., 1956. Statistical tables for use with binomial samples - contingency tests, confidence limits, and sample size estimates.Department of Medical Statistics, New York.

Moller, H., Norbury, G., and King C.M., 1996a. Ecological and behavioural constraints to effective control of ferrets (Mustela furo). In: Proc.Workshop on Tuberculosis in Ferrets, Royal Society of New Zealand, Christchurch, 27 - 28 March 1996.

Moller, H., Showers, J., and Wright, M., 1996b. Sodium monofluoroacetate (1080) poisoned jam bait laid for brushtail possums (Trichosurus vulpecula) also kills ferrets (Mustela furo). N.Z. J. Zool. 23: 135-141.

Morgan, D.R., 1981. Monitoring bait acceptance in brush-tailed possum populations: development of a tracer technique. N.Z. J. For. Sci. 11: 271-277.

Morgan, D.R., and Goodwin, M., 1995. Identification of 1080 paste suitable for use in the presence of bees. Landcare Research Contract Report: LC9596/03.

Morgan, D.R., Innes, J., Frampton, C.M., and Woolhouse, A.D., 1995. Responses of captive and wild possums to lures used in poison baiting.N.Z. J. Zool. 22: 123-129.

PCE., 1994. Possum management in New Zealand. Office of the Parliamentary Commissioner for the Environment, Wellington. 